\title{
THE IMPACT OF AEROSOLS ON CLOUD AND PRECIPITATION PROCESSES: CLOUD-RESOLVING MODEL
} SIMULATIONS

\author{
Wei-Kuo Tao ${ }^{1}$, Xiaowen $\mathrm{Li}^{1,2}$, Alexander Khain ${ }^{3}$, Toshihisa Matsui ${ }^{1}, 2$, Stephen Lang ${ }^{4}$, and Joanne Simpson ${ }^{1}$ \\ ${ }^{1}$ Laboratory for Atmospheres, NASA/Goddard Space Flight Center, Greenbelt, MD, 20771, USA \\ ${ }^{2}$ Goddard Earth Sciences and Technology Center, University of Maryland, Baltimore County, Baltimore, MD \\ ${ }^{3}$ Department of Atmospheric Science, Hebrew University of Jerusalem, Jerusalem, Israel
}

\section{INTRODUCTION}

Aerosols and especially their effect on clouds are one of the key components of the climate system and the hydrological cycle [Ramanathan et al., 2001]. Yet, the aerosol effect on clouds remains largely unknown and the processes involved not well understood. A recent report published by the National Academy of Science states "The greatest uncertainty about the aerosol climate forcing - indeed, the largest of all the uncertainties about global climate forcing - is probably the indirect effect of aerosols on clouds [NRC, 2001]." The aerosol effect on clouds is often categorized into the traditional "first indirect (i.e., Twomey)" effect on the cloud droplet sizes for a constant liquid water path [Twomey, 1977] and the "semi-direct" effect on cloud coverage [e.g., Ackerman et al., 2000]. Enhanced aerosol concentrations can also suppress warm rain processes by producing a narrow droplet spectrum that inhibits collision and coalescence processes [e.g., Squires and Twomey, 1961; Warner and Twomey, 1967; Wamer, 1968; Rosenfeld, 1999].

The aerosol effect on precipitation processes, also known as the second type of aerosol indirect effect [Albrecht, 1989], is even more complex, especially for mixed-phase convective clouds. Table 1 summarizes the key observational studies identifying the microphysical properties, cloud characteristics, thermodynamics and dynamics associated with cloud systems from high-aerosol continental environments. For example, atmospheric aerosol concentrations can influence cloud droplet size distributions, warm-rain process, cold-rain process, cloud-top height, the depth of the mixed phase region, and occurrence of lightning. In addition, high aerosol concentrations in urban environments could affect precipitation variability by providing an enhanced source of cloud condensation nuclei (CCN). Hypotheses have been developed to explain the effect of urban regions on convection and precipitation [van den Heever and Cotton, 2007 and Shepherd, 2005]. Please see Tao et al. (2007) for more detailed description on aerosol impact on precipitation.

Recently, a detailed spectral-bin microphysical scheme was implemented into the Goddard Cumulus Ensemble (GCE) model. Atmospheric aerosols are also described using number density size-distribution functions. A spectral-bin microphysical model is very expensive from a computational point of view and has only been implemented into the $2 \mathrm{D}$

Corresponding author's address: W.-K. Tao, Code 912 , NASA GSFC, Greenbelt, MD 20771, USA; E-Mail: Wei-Kuo Tao <Wei-Kuo.Tao-1@nasa.gov> version of the GCE at the present time. The model is tested by studying the evolution of deep tropical clouds in the west Pacific warm pool region and summertime convection over a mid-latitude continent with different concentrations of CCN: a low "clean" concentration and a high "dirty" concentration. The impact of atmospheric aerosol concentration on cloud and precipitation will be investigated.

\begin{tabular}{|c|c|c|c|}
\hline Properties & $\begin{array}{c}\text { High CCN } \\
\text { (Dirty) }\end{array}$ & $\begin{array}{c}\text { Low CCN } \\
\text { (Clean) }\end{array}$ & References (Observations) \\
\hline $\begin{array}{c}\text { Cloud } \\
\text { droplet size } \\
\text { distribution }\end{array}$ & Narrower & Broader & $\begin{array}{c}\text { Rosenfeld and Lensky [1998], } \\
\text { Rosenfeld [1999 \& 2000], } \\
\text { Rosenfeld et al. [2001], } \\
\text { Rosenfeld and Woodley } \\
{[2000], \text { Andreae et al. [2004], }} \\
\text { Koren et al. [2006], }\end{array}$ \\
\hline $\begin{array}{c}\text { Warm-rain } \\
\text { process }\end{array}$ & Suppressed & Enhanced & $\begin{array}{c}\text { Rosenfeld [1999 \& 2000], } \\
\text { Rosenfeld and Woodley } \\
{[2000], \text { Rosenfeld and }} \\
\text { Ulbrich [2003], Andreae et al. } \\
{[2004], \text { Lin et al. [2006] }}\end{array}$ \\
\hline $\begin{array}{c}\text { Cold-rain } \\
\text { process }\end{array}$ & Enhanced & Suppressed & $\begin{array}{c}\text { Rosenfeld and Woodley } \\
{[2000], \text { Orville et al. [2001], }} \\
\text { Williams } \text { et al. } \text { [2002], } \\
\text { Andreae et al. [2004], Lin et } \\
\text { al. [2006], Bell et al. [2007] }\end{array}$ \\
\hline $\begin{array}{c}\text { Mixed } \\
\text { phase } \\
\text { region }\end{array}$ & Deeper & Shallower & $\begin{array}{c}\text { Rosenfeld and Lensky [1998], } \\
\text { Williams et al. [2002], Lin et } \\
\text { al. [2006] }\end{array}$ \\
\hline $\begin{array}{c}\text { Cloud-top } \\
\text { height }\end{array}$ & Higher & Lower & $\begin{array}{c}\text { Andreae et al. [2004], Koren } \\
\text { et al. [2006], Lin et al. [2006] }\end{array}$ \\
\hline Lightning & $\begin{array}{c}\text { Enhanced } \\
\text { (downwind } \\
\text { side)/higher } \\
\text { max flash }\end{array}$ & $\begin{array}{c}\text { Less and } \\
\text { lower max } \\
\text { flash }\end{array}$ & $\begin{array}{c}\text { Williams et al. [2002], Orville } \\
\text { et al. [2001] }\end{array}$ \\
\hline
\end{tabular}

Table 1 Key observational studies identifying the differences in the microphysical properties, cloud characteristics, thermodynamics, and dynamics associated with clouds and cloud systems developed in dirty and clean environments. References of papers can be found in Tao et al. (2007).

\section{MODEL DESCRIPTION AND CASE STUDIES}

\subsection{GCE Model}

The model used in this study is the $2 \mathrm{D}$ version of the GCE model. Modeled flow is anelastic. Second- or higher-order advection schemes can produce negative values in the solution. Thus, a Multi-dimensional Positive Definite Advection Transport Algorithm (MPDATA) has been implemented into the model. All scalar variables (potential 
temperature, water vapor, turbulent coefficient and all five hydrometeor classes) use forward time differencing and the MPDATA for advection. Dynamic variables, $u, v$ and $w$, use a second-order accurate advection scheme and a leapfrog time integration (kinetic energy semi-conserving method). Short-wave (solar) and long-wave radiation as well as a subgrid-scale TKE turbulence scheme are also included in the model. Details of the model can be found in Tao and Simpson (1993) and Tao et al. (2003).

\subsection{Microphysics (Bin Model)}

The formulation of the explicit spectral-bin microphysical processes is based on solving stochastic kinetic equations for the size distribution functions of water droplets (cloud droplets and raindrops), and six types of ice particles: pristine ice crystals (columnar and plate-like), snow (dendrites and aggregates), graupel and frozen drops/hail. Each type is described by a special size distribution function containing 33 categories (bins). Atmospheric aerosols are also described using number density size-distribution functions (containing 33 bins). Droplet nucleation (activation) is derived from the analytical calculation of super-saturation, which is used to determine the sizes of aerosol particles to be activated and the corresponding sizes of nucleated droplets. Primary nucleation of each type of ice crystal takes place within certain temperature ranges. A detailed description of these explicitly parameterized processes can be found in Khain and Sednev (1996) and Khain et al. $(1999,2001)$.

\subsection{Case Studies}

Three cases, a tropical oceanic squall system observed during TOGA COARE (Tropical Ocean and Global Atmosphere Coupled Ocean-Atmosphere Response Experiment, which occurred over the Pacific Ocean warm pool from November 1992 to February 1993), a midlatitude continental squall system observed during PRESTORM (Preliminary Regional Experiment for STORM-Central, which occurred in Kansas and Oklahoma during May-June 1985), and mid-afternoon convection observed during CRYSTAL-FACE (Cirrus Regional Study of Tropical Anvils and Cirrus Layers Florida Area Cumulus Experiment, which occurred in Florida during July 2002), will be used to examine the impact of aerosols on deep, precipitating systems.

The June 10-11, 1985 PRESTORM case has been well studied (e.g., Johnson and Hamilton 1988; Rutledge et al. 1988; Tao et al. 1996; Lang et al. 2003). The PRESTORM environment was fairly unstable but relatively dry with a lifted index of -5.37 and a Convective Available Potential Energy (CAPE) of $2300 \mathrm{~J} / \mathrm{kg}$. The February 22, 1993 TOGA COARE squall line has also been well studied (Jorgensen et al. 1997; Trier et al. 1996, 1997; Wang et al. 1996). The CAPE and lifted index are moderately unstable, $1776 \mathrm{~J} / \mathrm{kg}$ and -3.2 , respectively. The CRYSTAL-FACE July 16, 2002 case is a sea breeze convection case that developed over South Florida [Ridley et al., 2004; Heymsfiedl et al., 2004]. It originated near the coast and propagated inland and dissipated within a couple of hours. The CAPE, total precipitable water and lifting index, are $2027 \mathrm{~J} / \mathrm{kg}, 4.753$ $\mathrm{g} / \mathrm{cm}^{2}$ and -4.23 , respectively,
A stretched vertical coordinate was used in the model with 31 grid points. There were 1024 horizontal grid points; the central 872 had a fixed 750,750 and $1000 \mathrm{~m}$ resolution for TOGA COARE, CRYSTAL and PRESTROM, respectively. The outer grids were stretched. Radiation was included, and a low-level cold pool was used to start the system.

\section{RESULTS}

\subsection{Rainfall and Its Characteristics}

Table 2 shows the domain-averaged surface rainfall amounts, and stratiform percentages for the TOGA COARE, PRESTORM and CRYSTAL-FACE cases under clean and dirty conditions. The precipitation is divided into convective and stratiform components [Tao et al., 1993; Lang et al., 2003]. The convective region includes areas with strong vertical velocities (over 3-5 $\mathrm{m} \mathrm{s}^{-1}$ ) and/or heavy surface rainfall. The stratiform region is simply non-convective. For the PRESTORM case, the dirty scenario produces more stratiform (light) precipitation than does the clean case. It is expected that a high $\mathrm{CCN}$ concentration allows for more small cloud droplets and ice particles to form. The lower collection coefficient for smaller cloud and ice particles allows for a larger amount of ice phase particles to be transported into the trailing stratiform region, producing a higher stratiform rain percentage in the dirty case. Aerosols do not have much impact on the straiform percentage for the CRYSTAL-FACE case because of its short life span. The reduction in stratiform rain (or light rain) in the dirty environment for the TOGA COARE case is due to its enhanced convective activity (stronger updrafts).

\begin{tabular}{|c|c|c|c|c|c|c|}
\hline & $\begin{array}{c}\text { TOGA } \\
\text { COARE } \\
\text { Clean }\end{array}$ & $\begin{array}{c}\text { TOGA } \\
\text { COARE } \\
\text { Dirty }\end{array}$ & $\begin{array}{c}\text { PRESTORM } \\
\text { Clean }\end{array}$ & $\begin{array}{c}\text { PRESTORM } \\
\text { Dirty }\end{array}$ & $\begin{array}{c}\text { CRYSTAL } \\
\text { Clean }\end{array}$ & $\begin{array}{c}\text { CRYSTAL } \\
\text { Dirty }\end{array}$ \\
\hline $\begin{array}{c}\text { Averaged } \\
\text { Rain }\end{array}$ & 18.0 & 28.4 & 38.3 & 29.1 & 12.6 & 11.0 \\
\hline $\begin{array}{c}\text { Stratiform } \\
(\%)\end{array}$ & 50 & 17 & 43 & 70 & 43 & 40 \\
\hline
\end{tabular}

Table 2 Domain-averaged surface rainfall amount (in $\mathrm{mm}$ day ${ }^{-1}$ ), stratiform percentage (in \%) for the TOGA COARE, PRESTORM and CRYSTAL-FACE case under dirty and clean conditions. Note there are 9 hours in the PRESTORM and TOGA COARE simulations, and 5 hours in the CRYSTAL-FACE simulation

Figure 1 shows time sequences of the GCE model-estimated domain mean surface rainfall rate for the PRESTORM, TOGA COARE and CRYSTAL cases. Rain suppression in the high $\mathrm{CCN}$ concentration (i.e., dirty environment) runs is evident in all three case studies but only during the first hour of the simulations. Rain reaches the ground early in all the clean cases. This is in good agreement with observations [e.g., Rosenfeld, 1999, 2000]. During the mature stage of the simulations, the effect of increasing the $\mathrm{CCN}$ concentration ranges from rain suppression in the PRESTORM case to little effect in the CRYSTAL-FACE case to rain enhancement in 
the TOGA COARE case. These results suggest that model simulations of the whole life cycle of convective system are needed in order to assess the impact of aerosols on precipitation processes associated with mesoscale convective systems and thunderstorms. These results also show the complexity of aerosol-cloud-precipitation interaction within deep convection.
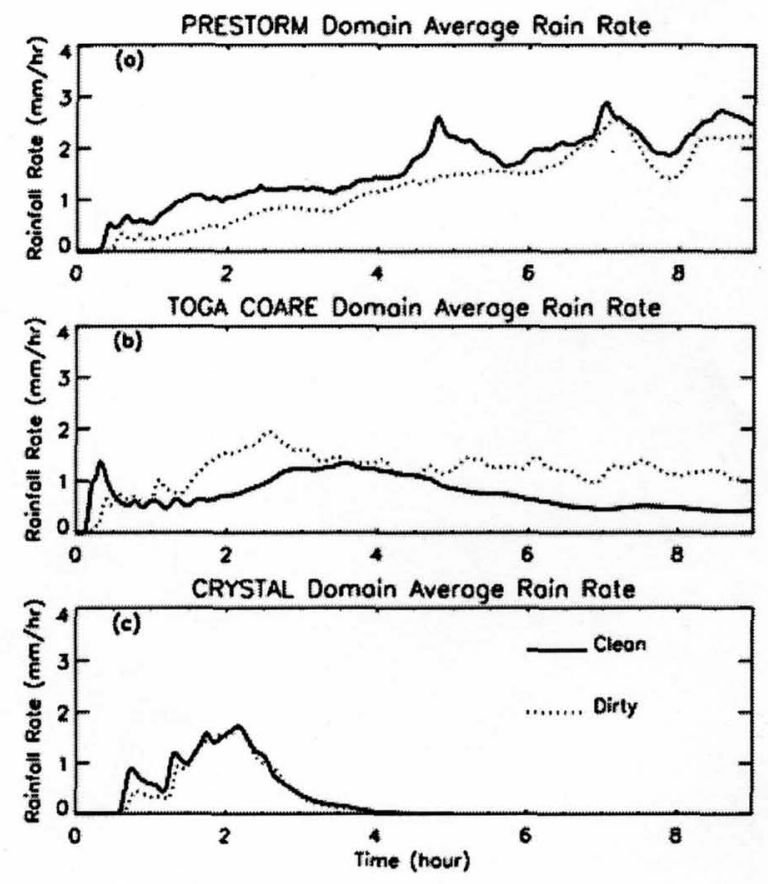

Fig. I Time series of GCE model-estimated domain mean surface rainfall rate $\left(\mathrm{mm} h^{-1}\right)$ for the (a) PRESTORM, (b) TOGA COARE, and (c) CRYSTAL case. The solid/dashed line represents clean/dirty conditions.

Figure 2 shows a schematic diagram of the physical processes that cause either enhancement (TOGA COARE) or suppression (PRESTORM) of precipitation in a dirty environment. In the early developing stages, small cloud droplets are produced in both the TOGA COARE and the PRESTORM cases with high CCN. Both cases also show narrower cloud drop size spectra for high CCN (not shown). This result is in good agreement with observations [i. e., Twomey et al., 1984; Albrecht, 1989; Rosenfeld, 1999]. In this early stage, rain is suppressed for both cases with high $\mathrm{CCN}$, which is also in good agreement with observations [e.g., Rosenfeld, 1999, 2000]. The suppression of precipitation in dirty conditions is mainly due to microphysical processes only. Smaller cloud droplets collide/coalesce less efficiently, delaying raindrop formation. These microphysical processes are very important especially in the early/developing stage of a cloud system.

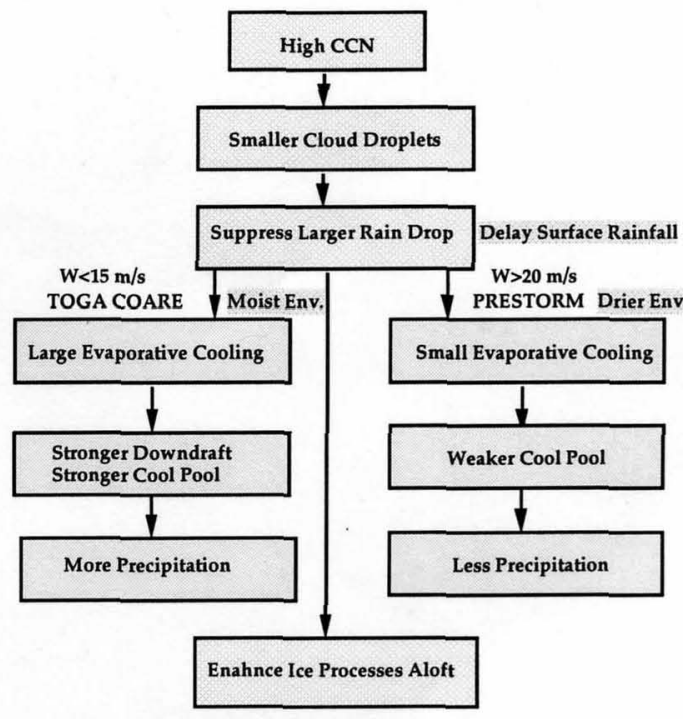

Fig. 2 Schematic diagram showing the physical processes that lead to either enhancement (TOGA COARE case) or suppression (PRESTORM case) of precipitation in a dirty environment. Adapted from Tao et al. (2007).

The model results also indicated that the low-level evaporative cooling is quite different between the clean and dirty case (Fig. 3). Stronger evaporative cooling could enhance the near surface cold-pool strength. When the cold pool interacts with the lower level wind shear, the convergence could become stronger, producing stronger convection for the dirty cases. This can lead to more vigorous precipitation processes and therefore enhanced surface precipitation (positive feedback) ${ }^{1}$. These processes seem to be occurring in the TOGA COARE case. In this case, evaporative cooling is more than twice as strong in the lower troposphere for the dirty scenario compared to the clean scenario. More rain reaches the surface after 30 minutes of model integration in the dirty case as compared to the clean case. During this period, more evaporative cooling in the dirty case is already evident from the model results.
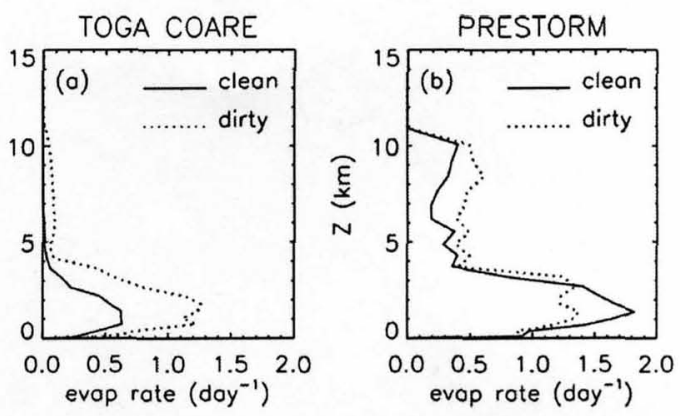

Fig. 3 Domain average evaporation rate $\left(\right.$ day $\left.^{-1}\right)$ profiles during the first two hour of simulation for the (a)

1 Note that the enhanced precipitation can cause enhanced evaporation that in turn has a positive feedback on the rainfall amounts by triggering additional convection. 
TOGA COARE and (b) PRESTORM case. The solid/dashed line represents the dirty/clean scenario.

\section{COMPARISON WITH PREVIOUS MODELING STUDIES}

Most previous modeling results found that high $\mathrm{CCN}$ concentrations could suppress precipitation processes [i.e., Khain et al., 2004, 2005; Cheng et al., 2007, Lynn et al., 2005b; Van den Heever et al., 2006; Teller and Levin, 2006; van den Heever and Cotton, 2007]. However, high CCN concentrations could also enhance precipitation processes [Wang 2005; Khain et al. 2005]. These results show the complexity of aerosol interactions with convection. More case studies are required to further investigate the aerosol impact on rain events. In almost all previous cloud-resolving modeling studies (including the present study), idealized or composite [i.e., van den Heever et al., 2006] CCN concentrations were used in the model simulations. In addition to IN and GCCN, the chemistry of CCN needs to be considered in future modeling of aerosol-precipitation interactions. In addition, many previous CRM studies did not compare model results with observed cloud structures, organization, radar reflectivity and rainfall. Some of the CRM domains were too small to resolve the observed clouds or precipitation systems (the domain size has to be at least twice as large as the simulated features). It may require major field campaigns to gather the data necessary to both initialize (with meteorological and aerosol) and validate (i.e., in situ cloud property observations, radar, lidar, and microwave remote sensing) the models. Although CRM-simulated results can provide valuable quantitative estimates of the indirect effects of aerosols, CRMs are neither regional nor global models and can only simulate clouds and cloud systems over a relatively small domain. Close collaboration between the global and CRM communities is needed in order to expand the CRM results to a regional and global perspective.

\section{SUMMARY}

- For all three cases, higher CCN produces smaller cloud droplets and a narrower spectrum. Dirty conditions delay rain formation, increase latent heat release above the freezing level, and enhance vertical velocities at higher altitude for all cases. Stronger updrafts, deeper mixed-phase regions, and more ice particles are simulated with higher $\mathrm{CCN}$ in good agreement with observations.

- In all cases, rain reaches the ground early with lower $\mathrm{CCN}$. Rain suppression is also evident in all three cases with high $\mathrm{CCN}$ in good agreement with observations (Rosenfeld, 1999, 2000 and others). Rain suppression, however, only occurs during the first hour of simulation. This result suggests that microphysical processes dominate the impact of aerosols on precipitation in the early stage of precipitation development.

- During the mature stage of the simulations, the effect of increasing aerosol concentration ranges from rain suppression in the PRESTORM case to little effect on surface rainfall in the CRYSTAL-FACE case to rain enhancement in the TOGA COARE case.
- The model results suggest that evaporative cooling is a key process in determining whether higher $\mathrm{CCN}$ reduces or enhances precipitation. Cold pool strength can be enhanced by stronger evaporation. When cold pool interacts with the near surface wind shear, the low-level convergence can be stronger, facilitating secondary cloud formation and more vigorous precipitation processes. Evaporative cooling is more than two times stronger at low levels with higher $\mathrm{CCN}$ for the TOGA COARE case during the early stages of precipitation development. However, evaporative cooling is slightly stronger at lower levels with lower $\mathrm{CCN}$ for the PRESTORM case. The early formation of rain in the clean environment could allow for the formation of an earlier and stronger cold pool compared to a dirty environment. PRESTORM has a very dry environment and both large and small rain droplets can evaporate. Consequently, the cold pool is relatively weaker, and the system is relatively less intense with higher $\mathrm{CCN}$.

- Sensitivity tests are conducted to determine the impact of ice processes on aerosol-precipitation interaction. The results suggested that ice processes are crucial for suppressing precipitation due to high $\mathrm{CCN}$ for the PRESTORM case. More and smaller ice particles are generated in the dirty case and transported to the trailing stratiform region. This reduces the heavy convective rain and contributes to the weakening of the cold pool. Warm rain processes dominate the TOGA COARE case. Therefore, ice processes only play a secondary role in terms of aerosol-precipitation interaction.

- Two of the three cloud systems presented in this paper formed a line structure (squall system). A 2D simulation, therefore, gives a good approximation to such a line of convective clouds. Since the real atmosphere is 3D, further 3D cloud-resolving simulations are needed to address aerosol-precipitation interactions.

\section{REFERENCES}

Tao, W.-K., X. Li, A. Khain, T. Matsui, S. Lang, and J. Simpson, 2007: The role of atmospheric aerosol concentration on deep convective precipitation: Cloudresolving model simulations. J. Geophy. Res., 112, D24S18, doi: 10.1029/2007JD008728.

\section{All other references can be found in above paper.}

\section{Acknowledgements}

The GCE model is mainly supported by the NASA Headquarters Atmospheric Dynamics and Thermodynamics Program and the NASA Tropical Rainfall Measuring Mission (TRMM). The authors are grateful to Dr. R. Kakar at NASA headquarters for his support of this research. The research was also supported by the Office of Science (BER), U. S. Department of Energy/Atmospheric Radiation Measurement (DOE/ARM) Interagency The authors are grateful to Dr. Kiran Alapaty at DOE/ARM for his support of this research. The authors acknowledge NASA Goddard Space Flight Center for computer time used in this research. 